\title{
AGUSTÍN DE ITURBIDE: \\ EL RECUERDO DE LA CONSUMACIÓN DE INDEPENDENCIA DURANTE EL SIGLO XIX
}

\author{
AGUSTÍN DE ITURBIDE: \\ THE MEMORY OF THE CONSUMMATION OF INDEPENDENCE \\ DURING 19TH CENTURY
}

Verónica Zárate Toscano

Instituto de Investigaciones Dr. José María Luis Mora

vzarate@institutomora.edu.mx

\begin{abstract}
The text analyses the celebrations of the consummation of independence throughout the nineteenth century. Following the proposal of the Lieux de Mémoire [realms of memory] and relying on hemerography, civic discourses and official documentation, it focuses on the process of building the civic calendar taking into account the inclusion or exclusion of certain events. It becomes evident how the powerful groups used the celebration to demonstrate their political affiliation at different historical times, thus contributing to the formation of national identity and historical memory byselecting memories and relegating oblivion.
\end{abstract}

Keywords: Iturbide, commemoration, consummation, memory.

\section{Resumen}

El texto analiza cómo se realizaron los festejos por la Consumación de Independencia en el siglo XIX. A partir de la propuesta de los lieux de mémoire [lugares de la memoria] y con base en hemerografía, discursos cívicos y documentación oficial, se considera el proceso de construcción del calendario cívico mediante la inclusión o exclusión de ciertos hechos. Se constata cómo los grupos en el poder utilizaron la festividad para patentizar su filiación política en los momentos en que se llevó a cabo, lo cual contribuye a la conformación de la memoria histórica, seleccionando los recuerdos y relegando los olvidos.

Palabras clave: Iturbide, fiesta, Consumación de la Independencia, memoria. 


\section{Introducción}

En las últimas décadas del siglo XX, Pierre Nora (Nora, 1984-1992) coordinó una obra monumental sobre la memoria francesa. Parte de mi quehacer historiográfico reciente se inspira en su propuesta metodológica para analizar la conformación de la memoria histórica a lo largo del siglo XIX y la manera en que se fue materializando a través de diversos aspectos que incluyen las conmemoraciones históricas. Cabría preguntarse por qué estudiar la memoria si no existe una memoria única: cada quien tiene una percepción del pasado, de la memoria, que es selectiva e incluye el olvido.

A lo largo de la historia, el Estado ha buscado homogeneizar la memoria, seleccionando los hechos sobre los que quiere que se base su presente y se fundamente su razón de ser, excluyendo todos aquellos que no estén acordes con sus intereses. Y precisamente en este largo proceso, los lieux de mémoire -y para el caso que nos ocupa ahora, las conmemoraciones- fueron una pieza clave en la edificación de la identidad nacional, que fue definida a partir del mito fundacional -como nación independiente- $\mathrm{y}$ apoyada por todos aquellos hechos que ayudaron a la conservación de México como un país libre. En el ámbito político, fueron utilizados como una vía para construir la historia de una nueva nación, difundiendo aquellos elementos culturales que conforman la identidad, la filiación política y los valores cívicos. Esa memoria es la que conforma los recuerdos individuales, grupales o nacionales y que forman parte de la identidad.

Los sucesos históricos no se limitan a un acontecimiento determinado en un día específico, sino que son parte de un proceso. Ese acontecimiento puede significar, por ejemplo, el inicio o el fin de una guerra, como la de Independencia, que tuvo un principio y un fin oficialmente datados: el 16 de septiembre de 1810 el padre Miguel Hidalgo arengó a un grupo de seguidores para luchar contra el "mal gobierno" y el 27 de septiembre de 1821 Agustín de Iturbide, junto con Vicente Guerrero y tropas insurgentes y realistas entraron a la ciudad de México en un acto que simbólicamente terminó la contienda. En los siguientes años, y a lo largo de buena parte del siglo XIX, se suscitó un debate sobre la preferencia por elegir uno de los dos días para realizar la celebración. Grosso modo, podríamos decir que unos grupos políticos -los llamados liberales- se inclinaron por el día del inicio, mientras que otros -los conservadores- escogieron el del final.

En 2021, el 27 de septiembre forma parte de una serie de conmemoraciones ligadas a la fundación de México-Tenochtitlan, la conquista de México y la Consumación de la Independencia. Estos dos últimos hitos representan el inicio y el final de la dominación española que duró tres siglos. Al conmemorar esas fechas específicas, se les está dotando de un simbolismo peculiar que ha caracterizado el análisis de la historia, como siempre, desde la perspectiva del régimen en turno. $Y$ es precisamente esa especificidad de cada momento la que le dota de dinamismo a este estudio y hace ver que los rituales festivos tienen rasgos que permanecen y otros que se transforman.

Ahora bien, el hecho tiene una duración determinada, pero su memoria es indeterminada: se le recuerda o se le olvida. El hecho en sí no cambia, lo que cambia es cómo se le rememora, se recuerda, se trae al presente, se le carga de connotaciones que le son extratemporales y lo vinculan a la historia de su tiempo. Un discurso parte de la base del hecho ocurrido: el 27 de septiembre de 1821 el Ejército Trigarante hizo su entrada a la ciudad de México, y con ello se consumó la Independencia. Pero este hecho es ajustado a las necesidades del momento en que se realiza la conmemoración y se pronuncia el discurso, por lo que se concede mayor o menor énfasis a algunos de los participantes, a las rutas que recorrió, a los espectadores.

Pero sobre todo puede interpretarse que forma parte de una predeterminación hacia la libertad o como una muestra de cómo cierto grupo buscó mantener un estatus al participar en un hecho inevitable. Y entonces, lo sucedido el 27 de septiembre pasa 
a un segundo plano, ya no importa lo que aconteció ese día, sino lo que ha pasado desde entonces, lo que implica el desarrollo de la nación independiente que vio la luz primera ese día.

En este texto analizaré cómo se realizaron los festejos por la Consumación de la Independencia a lo largo del siglo XIX, se tomarán en cuenta la decisión de incluir o descartar la conmemoración, los discursos cívicos pronunciados con motivo de la festividad y los actos conmemorativos. A través de estos aspectos se hará evidente la implicación política de las festividades a partir de los momentos en que se llevaron a cabo, vinculando así un hecho del pasado con un presente y vislumbrando un futuro. Podemos considerar que estas conmemoraciones son un catalizador que nos permiten analizar filias y fobias enfrentadas, las cuales convivieron en las primeras décadas del país recientemente independizado. Asimismo, son un aparador donde se podría ver y ser visto, participar y con ello adquirir notoriedad o simplemente sumirse en la pasividad.

El estudio se centra en la Ciudad de México, aunque se han hecho otros estudios sobre las festividades y los discursos de otras poblaciones, con sus matices regionales, por ejemplo, en Morelia, Puebla, Toluca, Querétaro, San Luis Potosí, Veracruz, Guadalajara, Zacatecas (Cañedo Gamboa y Salazar Mendoza, 2010; Connaughton, 1995; Denegre Vaught Alcocer, 2011; Departamento del Distrito Federal-Dirección General de Acción Social, 1955 y De la Torre Villar, 1988). ${ }^{2}$ Para el análisis, he recurrido a las noticias publicadas en los periódicos, a los discursos cívicos y a los expedientes conservados en el Archivo Histórico de la Ciudad de México (en adelante $A H C D M X)$, específicamente a los Fondos Municipales de la serie Festividades 15 y 16 de septiembre (1844: inv. 1067, exp. 25).

\footnotetext{
1 Se necesitaría más espacio del que se dispone en este artículo para mencionar y destacar los principales puntos tratados en los abundantes estudios sobre las festividades en general o los rituales de Iturbide en lo particular. El lector podrá ahondar sobre este aspecto en Garrido Aspero (2001), Vázquez Mantecón (2008) y Carbajal López (2017), entre otros.

2 Agradezco el apoyo de Jennifer Alejandra Romero Alfaro en la búsqueda de los discursos.
}

\section{El recuerdo en la agenda política}

En un recorrido por la prensa decimonónica y alguna documentación oficial, detecté en qué momentos se conmemoró el fin de la guerra de Independencia en una época tan inestable en que hubo tantos pronunciamientos, revueltas y cambios de quienes llevaban las riendas del país. Además, la naciente república no gozaba de tranquilidad permanente que le permitiera organizar conmemoraciones por verse involucrada también en distintos conflictos externos, como el intento de reconquista en 1829, la guerra e Independencia de Tejas en 1836, la guerra de los Pasteles en 1838, la invasión norteamericana de 1846-1848, la Intervención francesa de 1863-1867.

En septiembre de 1821 se consumó la Independencia, y ya para marzo de 1822 la Regencia había estipulado que las festividades nacionales serían los días 16 y 27 de septiembre (Priego y Hernández, 1985: 139-140). El 16 de agosto de ese mismo año, el Congreso Constituyente decretó que sería "día de corte" el "27 de septiembre por la entrada triunfante del ejército a la capital" (Dublán y Lozano, 1876a: t. I, n. 311). ${ }^{3}$ El emperador Agustín I no mostró demasiado interés por conmemorar la lucha recién terminada pero, después de la abdicación imperial en septiembre de 1823, al frente del país quedó el Supremo Poder Ejecutivo de la Nación Mexicana y decretó que los restos óseos de los caudillos insurgentes se trasladaran a la catedral metropolitana, con lo cual se rindió homenaje a los primeros héroes de la contienda.

El 10 de octubre de 1824 inició la presidencia de Guadalupe Victoria y pocos días después, el 14 de noviembre de 1824, el Congreso decretó la "solemne celebración del 16 de septiembre” (Dublán y Lozano, 1876b: t. I, n. 442). En atención a dicha disposición, iniciaron los preparativos para la primera gran conmemoración. En agosto de 1825, la prensa hizo eco de la necesidad de "eternizar con cívicos ceremoniales el aniversario de su libertad", de tal modo que se prepararon los

\footnotetext{
3 Véase, para más detalle a Garrido Aspero (2001).
} 
primeros festejos de la Independencia. Aún no se había contemplado la inclusión del 27 de septiembre; simplemente había que hacer extensivo a todo el país el festejo de la Independencia, y lo más recomendable era pronunciar "una alocución lacónica, enérgica y propia de la celebridad, la que debiera imprimirse para que sirviese de recuerdo glorioso en el discurso de todo el año" (Aguila Mejicana, 28 de agosto de 1825: 1).

Durante la presidencia de Victoria no se efectuó una conmemoración específica el día de la Consumación. Sólo encontramos, en el periódico Aguila Mejicana del 27 de septiembre de 1827, una nota recordando que habían pasado seis años desde que el Trigarante había consumado "la obra de nuestra feliz emancipación y entró en esta capital triunfante y glorioso". Y también se aprovechó la nota para recomendar que, a las garantías de independencia, religión y unión, se agregara la de "federación, que es la forma de gobierno que nos libró de la guerra civil y fijó para siempre la felicidad del Anáhuac" (Aguila Mejicana, 27 de septiembre de 1827: 4).

En 1829, México se enfrentó al intento de reconquista español al frente de Isidro Barradas. Antonio López de Santa Anna logró repeler la invasión y, con su victoria, el 11 de septiembre, la convirtió en la fecha a conmemorar en los años por venir, mientras estuviera en la silla presidencial. El gran artífice de esta celebración fue José María Tornel, quien decretó que las festividades del 15, 16 y 27 de septiembre se dedicaran a celebrar la victoria de Santa Anna (Fowler, 2010: 178), y en 1834 se decretó que el 11 de septiembre se volviera una fiesta nacional.

En 1831, al frente del país se encontraba Anastasio Bustamante y con él se puede decir que empezó a figurar la celebración de la entrada del Trigarante. Ese año encontramos publicado en la prensa un himno cívico de Ignacio Sierra y Rosso con música de José Castel que se cantó en el Teatro Principal el 27 de septiembre (Sierra y Rosso, 1831: 3-4):

iOh! feliz el instante en que vimos a los libres en México entrando, sus penosas tareas acabando y a la patria valientes salvar mas dichosos por fin si reunidos respetar nuestras leyes sabemos y de aquellos trabajos podemos venturosos los frutos lograr.

Además de exaltar el hecho histórico, aparece la esperanza de que, respetando las leyes, se recojan los frutos de la libertad.

No tenemos registro de que se efectuaran conmemoraciones por la Consumación en los siguientes años, sino hasta 1837 en que nuevamente encabezó el Ejecutivo el antiguo realista Bustamante, en una república centralista, apoyada en Las Siete Leyes.

En 1837 habían pasado ya 16 años desde la Consumación de la Independencia y este hecho formaba ya parte de los recuerdos de los que la habían presenciado o participado en ella. El editor del periódico Diario de Gobierno, salido de la imprenta del Águila de José Ximeno, escribió que la memoria mágica de ese momento "aún hace palpitar de gozo los pechos y baña los ojos en dulcísimo llanto" (Diario del Gobierno de la República Mexicana, 27 de septiembre de 1837: 108). Tal vez uno de los conmovidos era el propio Bustamante, quien a los 40 había cabalgado en la citada entrada y a los 57 tenía especial interés por exaltar a Iturbide, y la hazaña de dar por terminada la guerra.

Bustamante fue, además, el artífice del rescate de los restos mortales de Agustín de Iturbide, enterrados en Padilla, Tamaulipas, lugar de su fusilamiento. Ordenó que se trasladaran a la ciudad de México y se depositaran en la catedral metropolitana el 27 de septiembre de 1838, lo cual coincidió con la entrada del Trigarante. Por diversas circunstancias, el depósito se hizo hasta el 27 de octubre, fecha de la conmemoración de la jura de la Independencia (Zárate Toscano, 1994). De cualquier manera, el día de la Consumación se celebró con todo "el júbilo, la solemnidad y la pompa" (Diario del Gobierno de la República Mexicana, 28 de septiembre de 1838: 112).

Fue el 6 de septiembre de 1843 cuando Antonio López de Santa Anna decretó que 
el 27 sería fiesta nacional "en memoria de que en igual día del de 1821 ocupó el Ejército Trigarante la capital de la república" (Dublán y Lozano, 1880: t. IV, n. 2657). En adelante, hubo conmemoraciones casi todos los años, por ejemplo, al revisar la prensa de 1861, no encontramos que se haya conmemorado la Consumación. En el discurso pronunciado el 16 de septiembre, Ignacio Ramírez se refería a Iturbide, igual que a Santa Anna y Bustamante, como un cadáver político (Ramírez, 1861; y Malo, 1948: 643). ${ }^{4}$ Pero al mismo tiempo que se manifestaba ese desprecio, en el Teatro Iturbide se presentaba "el drama en tres actos y en verso, titulado El abrazo de Acatempan o el primer día de la bandera nacional" (El Siglo Diez y Nueve, 16 de septiembre de 1861: 4; y El Siglo Diez y Nueve, 27 de septiembre de 1861: 4). Los autores eran Juan A. Mateos y Vicente Riva Palacio, nieto de Vicente Guerrero, y tal vez por ello estuviera más encaminada a su reivindicación que a la de Iturbide (Vásquez Meléndez; 2012).

Cuando Maximiliano de Habsburgo ascendió al trono que había ocupado Agustín de Iturbide como primer emperador, podría pensarse que daría importancia a las conmemoraciones tan apreciadas por algunos sectores conservadores, pero el segundo emperador mostró tendencias más cercanas a las ideas liberales. $Y$ fue precisamente él quien suprimió oficialmente la conmemoración de la Consumación resolviendo que "en el día 16 de septiembre de cada año se reúnan los gloriosos recuerdos del 16 de 1810 y del 27 de 1821" (Zárate Toscano, 2004: 189; AHCDMX, 1864: inv. 93, exp. 34). En los años por venir desaparecería oficialmente la conmemoración de la Consumación, aunque la prensa registró actividades de algunos sectores de la sociedad que la seguían recordando, pero sobre todo celebraban el papel de Agustín de Iturbide. Cuando en 1883 se cumplió el centenario de su nacimiento, renació la festividad, incluso con la participa-

4 "Este día ha quedado excluido de las fiestas nacionales y en los discursos del 16 un orador dijo: que aquel plan (de Iguala), fue una rémora para la Independencia, y otros que Iturbide era un cadáver político" Malo (1948: 643). ción de una Junta Patriótica para organizar los actos. Entre ese año y 1921, centenario de la Consumación, ${ }^{5}$ hubo esporádicas demostraciones de adhesión a Iturbide y esfuerzos porque no desapareciera su memoria (Zárate Toscano, 2007).

\section{El recuerdo en la palabra oral e impresa}

Una forma de difundir las ideas en torno a la historia, al pasado, a las acciones políticas, realizadas por egregios hombres que entraron en el panteón de los héroes, es a través de los discursos que se pronuncian en las festividades oficiales. ${ }^{6}$ Se han englobado en la categoría de oraciones cívicas, alocuciones, discursos patrióticos y seguían la tradición de los sermones religiosos. ${ }^{7}$ En otro lado me he ocupado de analizar algunas oraciones cívicas para demostrar el amor a la patria (Zárate Toscano, 2013), y ahora lo haré en función de la exaltación de la Consumación de la Independencia y de quiénes lo lograron. Pero además de esas expresiones orales que se pueden ir con el viento, existe el recurso de imprimirlas para fijar el recuerdo e incidir políticamente; ya fuera en forma de publicaciones sueltas como folletos o libelos o incluidas en los periódicos, tenemos la fortuna de que se han conservado en distintos repositorios bibliográficos o hemerográficos, y nos permiten acceder a ellas para someterlas al análisis discursivo, para reconstruir las ideas del pasado y reconocer el papel de la palabra y de las letras. ${ }^{8}$

5 Algunos textos que se ocupan de las celebraciones de 1921 son Guedea (2009), Tapia R-Esparza (2010) y Moreno Juárez (2012).

6 En los discursos hacen referencia a ciertos personajes, hechos, filosofía, los cuales se identifican con la posición política del orador.

7 En las fuentes consultadas se enlistan varios estudios sobre los discursos conmemorativos. Véase Connaughton (2005), Herrejón Peredo (2003) y Plasencia de la Parra (1991).

8 Dejaré para otro momento la comparación entre los discursos pronunciados para conmemorar el inicio y la Consumación de Independencia. Por falta de espacio, tampoco me ocuparé de hacer un análisis del contenido histórico de cada uno de ellos, mas destaco el tratamiento que dan a los héroes de cada momento, a la manera como lo hizo Virginia Guedea (2009) para los discursos pronunciados en 1910 y 1921. 
Los discursos patrióticos pronunciados en las festividades cívicas tienen características comunes, entre ellas, tomar como pretexto el motivo de la celebración para exaltar a sus protagonistas, pero también para expresar las ideas de los oradores sobre determinados puntos. Algunos hacían un relato detallado de las acciones que culminaron en el hecho trascendental que motivó tal festejo, en este caso, la entrada del Ejército Trigarante a la ciudad de México para dar fin a la guerra y consumar así la Independencia. Tal es el caso del discurso pronunciado por el ciudadano Lic. José María Aguilar de Bustamante el 27 de septiembre de 1837 (Aguilar de Bustamante, 1837).

Otros apenas se ocupaban de los hechos históricos, aunque sí resaltaban a los héroes o a los protagonistas de tal acción. En varios discursos encontramos más alusiones al presente -o al pasado reciente- que al momento que se conmemoraba. Por ejemplo, para demostrar el triste estado en que se encontraba el país tras la invasión norteamericana, ${ }^{9}$ el orador José González Mendoza se fue hasta los tiempos de Cartago para recoger aquellas acciones bélicas que habían llevado a la ocupación de territorios por parte de los enemigos de una nación. Igualmente era factible desmenuzar las causas internas que habían facilitado tal desastre, como las divisiones internas, las políticas equivocadas, los errores cometidos, la corrupción, el lujo, la indiferencia. En cierto sentido, muchos discursos se volvían un catálogo de agravios y una forma de culpar a una política exterior e interior maliciosa. Pero también eran una manera de exaltar a los que habían dado la vida luchando para impedir los trastornos de la nación. Habría la posibilidad de proponer soluciones, de encender el espíritu patriótico para encaminar a la ciudadanía a comprender sus deberes y "con nobleza y buena fe trabajemos por llenarlos" (González Mendoza, 1848: 1). Lo importante es que los discursos excitaban el nacionalismo entre los escuchas o lectores.

9 Will Fowler (1998: 265-269) destaca el pesimismo de la clase política después de la invasión norteamericana, el cual se reflejó en los discursos cívicos.
No podemos pasar por alto el contexto en que se produjeron estas piezas oratorias, pero si lo vinculamos con las características de inestabilidad política del siglo XIX, entendemos el tono en que fueron pronunciados. En 1845, Joaquín Navarro e Ibarra captó la atención de su público diciendo: "los pueblos, como los hombres, cuando el actuar infortunio los agobia, se sienten impulsados a mirar hacia atrás y a consolarse con los serenos y plácidos recuerdos de los tiempos en que les sonreía grata la fortuna" y hacía referencia al triste estado en que se encontraba México por culpa de los bandos civiles y oprimido por el peso del despotismo, la crisis económica y la guerra (Navarro, 1845: 3). En muchos casos resaltaba el pesimismo, como cuando, en 1849, Santiago Blanco pintaba un cuadro dramático al reconocer que poco se había hecho para conservar la herencia legada por los héroes y que "la generación de la gloria ha desaparecido para dar lugar a la del dolor y del infortunio" (Blanco, 1849: 2).

Algo que no podían evitar los oradores era dar cuenta del paso inevitable del tiempo y algunos llegaron a comparar el pasado con el presente. Manuel Fernández de Jáuregui se desgarraba el alma al comparar

a México de 1821 con México de 1860; porque la una joven y lozana, coronada por la victoria, rica y respetada, veía a naciones poderosas disputarse su amistad y tenía la certeza de que el día de peligro, todos sus hijos se agruparían en derredor de la bandera tricolor para servirle de escudo; mientras que la otra, deshojados sus laureles, desmembrado su territorio, menospreciada su amistad, mira a sus hijos degollarse unos a otros, dejarla sin defensa y facilitar la ejecución de los pérfidos proyectos, de amigos desleales o de solapados enemigos (Fernández de Jáuregui, 1860: 1).

Estas palabras retrataban la desolación provocada por el deterioro del país. En otros discursos surgía un deseo conciliador cuando se sugería borrar lo malo del pasado, buscar los medios de enfrentar el presente y construir un mejor futuro a pesar de los di- 
versos acontecimientos políticos internos y externos que condicionaron el desarrollo de México como un país independiente. Cuando permeaba el optimismo, aparecía con la intención de dar aliento a los mexicanos para reparar lo perdido. José María Castillo Velasco expresaba en 1855 que "cuando la generación de héroes que sostuvo la guerra de independencia" había comenzado a desaparecer, surgió otra dispuesta a defender la libertad por lo que arengaba: "iPueblo! Perdón y olvido para lo pasado; para el porvenir, ife y esperanza!" (Castillo Velasco, 1855: 1). En el fondo, el deseo era que la conmemoración animara "el amor al suelo, la gloria, el honor, la unión, la religión y la libertad". Textos como éste daban cuenta del vaivén de las emociones y de la necesidad de motivar a los mexicanos para mejorar su situación que empeoraba día con día.

Así pues, en algunos discursos encontramos una combinación de nostalgia, lamento y una invitación a combatir una situación negativa. En 1846, José María Godoy consideraba que "hubo en tiempo para la nación mexicana en que el recuerdo solemne de sus glorias, la conmemoración anual" se celebraba con general regocijo, sin ideas tristes ni melancólicas, todos olvidaban sus privaciones y al inicio de los actos conmemorativos dejaban sus penas en casa y salían "con el semblante risueño y apacible para presentarse en los lugares públicos". A continuación, se lamentaba que "fue, por desgracia, de muy corta duración tan venturosa época" e iniciaba el relato de las desgracias y las críticas. Después de una larga alocución, terminaba excitando a sus compatriotas a "combatir unidos no sólo contra las armas opresoras de nuestros invasores de los Estados Norte-americanos sino también contra la política engañosa de los viles" (Godoy, 1846: 3). Ante el avance del enemigo, había la imperiosa necesidad de defender el suelo patrio para que no perdiera la independencia que había ganado en 1821.

Una parte importante de la organización de las festividades cívicas recaía en una Junta Patriótica (Costeloe, 1997). Una de sus funciones era la selección del orador encargado de pronunciar el discurso alusivo. Incluso, si las finanzas lo permitían, se le entregaba un "obsequio" y se mandaba publicar la pieza oratoria o, en todo caso, se incluiría en la prensa. Las crónicas y descripciones no aluden a la participación de oradores espontáneos. Parece poco creíble que se controlara su presencia en la ciudad de México, pero no puede descartarse esa posibilidad, tal vez con más frecuencia en los alrededores que en el centro.

Lo que sí es un hecho es que, lo que en las festividades se pronunciaba, se preparaba con anticipación y más aún si se esperaba que el texto se plasmara en tinta y papel para ser distribuido el día de la festividad. En cierto sentido, dichas piezas oratorias formarían parte del discurso oficial y se esperaba que los encargados de pronunciarlas no profirieran críticas al gobierno o expresaran ideas políticamente incorrectas. Sin embargo, encontramos un caso que demuestra que no todos ellos tenían la aceptación oficial.

En 1843, la Junta Patriótica seleccionó como orador a uno de sus integrantes, José María Lafragua, abogado y literato. Según él mismo admitió, aceptó el encargo "decidido a no seguir más que los impulsos de mi corazón y a decir, con la franqueza de un hombre de bien, cómo he sentido y juzgado los acontecimientos prósperos y adversos de nuestra historia" (Lafragua, 2014: 32). Preparó su texto, lo compartió con amigos cercanos y lo entregó a la imprenta de Vicente García Torres.

La "arenga cívica" iniciaba resaltando que "el aniversario del nacimiento de un hombre es el día más hermoso para una familia; el aniversario de la Independencia de un pueblo es el día más grande para una sociedad". Exponía que sus objetivos eran "memorar el venturoso principio de la era mexicana y excitar en los corazones sentimientos de amor al beneficio, de gratitud al bienhechor, y, lo diré también, de arrepentimiento por el mal uso que hemos hecho de la libertad" (Lafragua, 2014: 32).

Las siguientes páginas estaban dedicadas a hacer un recuento histórico desde la 
conquista hasta la Independencia. Cuando hablaba de Miguel Hidalgo, Ignacio Allende, Juan Aldama y Mariano Abasolo decía que no habían logrado ver la Independencia "más que con los ojos de la esperanza". El relato continuaba y, tras identificar a $\mathrm{Vi}$ cente Guerrero como sencillo y puro como los primeros romanos y "constante y noble como él solo", y a Iturbide ${ }^{10}$ como "amado en el ejército, temido por los que fueran sus contrarios y enorgullecido justamente con la conciencia de su superioridad", llegaron a Acatempan que "fue el anillo que enlazó a Dolores con Iguala" con la entrada del Trigarante "un diluvio de felicidad inundó a la hermosa México" e Iturbide pronunció su famosa frase: "ya sabéis el modo de ser libres; a vosotros toca señalar el de ser felices".

Lafragua lamentaba que el día venturoso que se conmemoraba fue el último día sereno que amaneció el caudillo: "se durmió sobre un trono y despertó en un cadalso [...] Cometió faltas, pero el crimen de Padilla las borró”. Y a continuación venían las críticas y reclamaciones: "conquistamos la independencia, pero... ¿̇y la libertad? ¿qué cuenta daremos de ella a Hidalgo, a [José María] Morelos, a Guerrero y a Iturbide si, levantándose de sus tumbas, nos preguntan qué hemos hecho de la rica herencia que nos dejaron". Criticaba el paso "de un sistema a otro y de un gobierno a otro y de una a otra facción" y recalcaba que se habían "vivido lustros enteros sin ver el semblante de la paz". Resaltaba las consecuencias de la inmoralidad de las naciones que se dicen víctimas de un déspota, no siéndolo más que de sus propias locuras y maldades y pintaba un funesto panorama si se continuaba por esa vía e invitaba a arrancar a "los partidos la hipócrita máscara con que se encubren y denunciémoslos ante la patria como reos de lesa libertad" (Lafragua, 1843: 3).

En la noche del 26 de septiembre, lo buscaron en su casa porque "el gobierno sabía

10 El 27 de septiembre de 1898, el periódico La Voz de México que tanto se ocupaba de Iturbide, particularmente durante el centenario de su nacimiento, publicó unos versos firmados por José María Lafragua que habían sido publicados en el Apuntador en 1841. Se incluyeron en América Poética (1846). Eran una vindicación del libertador. que mi discurso era sedicioso". El propio Lafragua escribió su versión de los hechos para defender su reputación afectada por lo publicado en la prensa (El Siglo Diez y Nueve, 30 de septiembre de 1843: 2-3; Diario del Gobierno de la República Mexicana, 28 de septiembre de 1843: 111). Tanto el Siglo Diez y Nueve como el Diario del Gobierno de la República Mexicana afirmaban que el discurso "estaba lleno de máximas, no solo demasiado alarmantes y subversivas, contrarias al orden, a la tranquilidad y al respeto debido a las Bases Orgánicas juradas por la nación, sino también contrarias al buen nombre del supremo gobierno", por lo que debía impedirse que se pronunciara y circulara, además de castigar al autor.

Las autoridades exigieron la entrega del original para que fuera dictaminado por el letrado José María Puchet, mientras Lafragua permanecía detenido e incomunicado y así pasó el día de la Consumación, hasta que fue liberado a la mañana siguiente. La versión de la prensa decía que el censor había considerado que la segunda parte del discurso, en la que Lafragua se proponía manifestar el arrepentimiento que debía existir por "el mal uso que hemos hecho de nuestra libertad", sí contenía proposiciones avanzadas criticando que se había abusado de la libertad.

En suma "todo el cuadro de nuestra ignominia que pinta el autor" era ajeno a la celebridad del objeto y era deshonroso a la nación y al gobierno que la presidía. Puchet cerraba diciendo que, aunque el orador había hecho duras críticas, su intención había sido, como la de otros que lo habían precedido en la tribuna, que la nación reconociera y reformara sus defectos, que el "patriotismo tiene también su exaltación, como la oratoria sus fervores, merece disculpa su celo". Consideraba que las disposiciones adoptadas no habían tenido otros fines "que el de sostener firme e irrevocablemente los derechos de la nación, procurando impedir de todos modos cuanto tienda a ofenderla y degradarla" y que "jamás se mancille el buen nombre de la república y, mucho menos por los mismos mexicanos" (El Siglo Diez y Nueve, 30 de 
septiembre de 1843: 2-3 y Diario del Gobierno de la República Mexicana, 28 de septiembre de 1843: 111).

Por su parte, Lafragua comentó que él se había limitado a denunciar las maldades de las facciones, que su conciencia estaba tranquila y que esperaba sin temor el fallo de la opinión. A pesar -o precisamente a causa de la censura- el discurso se había vendido en "secreto a peso de oro y fue publicado en Nueva Orleans, en francés e inglés con notas de Farías". Por si fuera poco, lo había pronunciado en una comida que le ofrecieron sus amigos al día siguiente que lo liberaron.

De este recuento resalta el hecho de que los problemas de censura no fueron causados por criticar la Consumación de la Independencia o a los que la habían conseguido, sino por criticar el faccionalismo que tanto daño causaba al país. Palabras más, palabras menos, ese tema había estado y seguiría estando presente en las piezas de oratoria, pues era difícil ocultar la inestabilidad del país y los enfrentamientos entre facciones. La historiografía tradicional ha calificado este periodo como el escenario de una lucha entre liberales y conservadores, pero esta visión bipartita ha sido muy rebatida. Más bien se ha señalado la existencia de todo un crisol de posturas entre los políticos que, además, podían acercarse a los ideales de un grupo y en seguida renegar de ellos y combatirlos, lucha que, a los ojos de Lafragua, era perniciosa para la libertad y por ejercer su derecho a expresarse, había enfrentado la censura. Su forma de contar la historia se había convertido en un delito.

El tono usado en los discursos variaba mucho en función del momento en que se pronunciaba y de las filias de quien lo declamaba. Sin embargo, resalta un obvio punto en común que era el deseo de enaltecer al consumador de la Independencia, pero la variante se detectaba en torno al papel que había desempeñado. A veces llegaban a adquirir un acento providencial que convertía a Iturbide en el "Ángel que el Señor volvió instrumento de la providencia”. Y su protagonismo era tal, que opacaba al resto de los militares que participaron en la entrada a la ciudad de México. Pero no se podía hacer caso omiso de los que se consideraban sus mayores errores. En 1854, Agustín Sánchez de Tagle manifestó que desearía no turbar con tristes reflexiones un día de júbilo, sino borrar de la memoria el recuerdo de los males públicos. Reconoció que después de la Consumación se habían minado las sólidas bases sobre las que se había construido y que lo sucedido se había atribuido a "miras innobles del Caudillo" a quien se "le hizo aparecer a los ojos del mundo como devorado por una ambición desmesurada" (Sánchez de Tagle, 1854: 2). Con estas palabras buscaba deslindar la responsabilidad de Iturbide en su ascensión al trono imperial.

José María Tornel nunca ocultó su admiración por Iturbide y no dudó en reconocer en 1850 que estaba "predestinado para la redención de su patria como lo fue Moisés" y que el "Altísimo" lo había dotado de "claro talento, de señalado valor, de incansable actividad". Era "uno de esos hombres extraordinarios que raras veces aparecen en la escena del mundo" por lo que rogaba a Dios "que, a la víctima inocente de Padilla, concedas allá en los cielos donde los ángeles y querubines son el escabel de tus plantas, la diadema de los mártires, la recompensa que has ofrecido a los bienhechores de los hombres" (Tornel y Mendívil, 1850: 3).

El editor de El Siglo Diez y Nueve, Ignacio Cumplido, por ejemplo, después de alabarIo, criticó que, en 1822, "aquél a quien se había creído un Washington, se dejó coronar como emperador. Mas debemos echar un velo sobre sus errores para solo acordarnos de su gloria" (El Siglo Diez y Nueve, 27 de septiembre de 1844: 3). Y ese tono conciliador se hizo presente en varias de las piezas oratorias. Hubo quien, como José Mariano Monterde, justificaba el que hubiera aceptado ceñirse la corona para después abdicar "imponiéndose a sí mismo el sacrificio de la expatriación de que hay pocos modelos en la historia", despidiéndose convencido de que no se había presentado la necesidad de otro sacrificio. Y cuando fue sacrificado, sus últimas palabras fueron "Unión, mexicanos" y el orador lamentaba que no las habían 
"querido escuchar y nuestros males suben de punto" (Monterde, 1852: 8).

No olvidemos que Iturbide entró a la ciudad de México al frente del Ejército Trigarante y cabe hacer notar que varias oraciones conmemorativas fueron pronunciadas por militares. En una de ellas, en 1851, el general Joaquín Rangel enfatizaba que se encargaría de "vindicar a los restos de este ejército de las imputaciones que le hacen gentes vulgares o ignorantes", sobre todo a raíz de las derrotas sufridas ante los norteamericanos (Rangel, 1851: 4). El otro protagonista del "Abrazo de Acatempan" y de la Consumación de Independencia, Vicente Guerrero, también fue mencionado en los discursos, aunque no con tanta frecuencia como Iturbide. José María Godoy se indignaba por el

asesinato inicuo en la persona del patriota ilustre don Vicente Guerrero, aquel mexicano que adquirió un lugar excelso entre los héroes, sus compatriotas, allá en el templo de la inmortalidad, porque con su constancia singular y portentosa en sostener la independencia de la patria, probó hasta la evidencia que era su alma de un temple exquisito (Godoy, 1846: 3).

Todos los anteriores son muestra de las opiniones sobre la Consumación de Independencia y sobre el propio Iturbide. Pero recordemos que el discurso era también la ocasión de emitir críticas, unas más veladas que otras, a la manera en que se habían conducido los destinos del país y excitar a los ciudadanos para que estuvieran prestos a defenderlo ante la adversidad.

Ahora bien, respecto a la "honrosa tarea" del orador, en 1844, Guillermo Prieto inició su alocución así:

En un día en que la voz del patriotismo evoca nuestros más dulces recuerdos, en que el orgullo y la ternura cívica recorren una de las más brillantes páginas de nuestra historia, porque es lisonjero siempre heredar el renombre de nuestros padres, la voz del orador, expresión viva de todos los sentimientos, eco sonoro de todos los afectos, debe ser, y no más, un cántico de júbilo, un himno de entusiasmo, un clamor de esperanza nacional (Prieto, 1844: 3).
Respecto a los espacios seleccionados para pronunciar los discursos, para establecer las tribunas desde las que los oradores se dirigían a las comitivas oficiales y a la multitud congregada, éstos solían ser lugares abiertos. La glorieta central de la Alameda de la ciudad de México fue el lugar privilegiado para el discurso. Castillo Velasco vislumbraba el momento de la alocución como un

iHermoso cuadro! La multitud que se agolpa alrededor de la tribuna, los árboles que levantan su follaje descubriendo entre sus ramas el azul purísimo de nuestro cielo y sobre todo esto desplegando su oriflama y ondeando sobre nuestras cabezas el pabellón tricolor de Iguala. iHermoso cuadro! (Castillo Velasco, 1855: 114).

También era factible declamarlas en espacios cerrados. Entre los discursos que hemos recogido encontramos que algunos tuvieron lugar en un acto celebrado en "el general de la Universidad", pero eso limitaba el número de asistentes.

Los oradores para esta conmemoración no eran distintos de los que pronunciaban los discursos por el 16 de septiembre y pertenecían a cuerpos civiles y militares e incluso algunos se mencionaban sólo como "ciudadanos". En 1844, Guillermo Prieto era "Empleado en la renta del tabaco" (Prieto, 1844), José María Tornel en 1850 se presentaba como "ciudadano, senador, general de división” (Tornel y Mendívil, 1850), y José Mariano Monterde, en 1852, era director del Colegio Militar (Monterde, 1852).

Todos contribuyeron, a su manera, a mantener en la palestra los nombres de los protagonistas de la Consumación que se conmemoraba, pero también dieron pie a una discusión sobre la situación en que se había sumergido el país una vez obtenida la independencia, a los peligros y amenazas externas que había enfrentado, a las rencillas internas que habían mancillado los ideales por los que habían luchado. Y dentro de todo esto, había que salvaguardar la memoria de los héroes. Algunos oradores se 
sentían avergonzados en pensar que, desde ultratumba, esos excelsos varones verían con profunda tristeza lo que había quedado después de sus acciones. Por eso los usaban como un detonante para estimular a los ciudadanos para que buscaran la manera de contribuir a la felicidad y desarrollo de México. El pasado se ponía al servicio del presente.

\section{El recuerdo en las acciones conmemorativas}

Conmemorar significa traer a la memoria, recordar, revivir un acontecimiento. $Y$ para lograrlo, se recurre a distintos mecanismos encaminados a fijar ese recuerdo. En los rituales festivos se pueden reconocer tres planos secuenciales: actos preparatorios, centrales y complementarios (González Pérez, 1995: 14).

Dentro de los actos preparatorios se incluye todo aquello realizado por los organizadores. Durante buena parte del siglo XIX, la organización recaía en una Junta Patriótica, compuesta por personajes prominentes vinculados a las instituciones, a las actividades comerciales y a la sociedad civil (Costeloe, 1997). Los actos preparatorios incluían la selección de los oradores para cada festividad, el reparto de invitaciones y la publicación de los programas. Sin embargo, una de sus principales funciones era la recolección de donativos para el financiamiento de las festividades." Si bien existía una partida específica para conmemoraciones en el presupuesto del Ayuntamiento (Zárate Toscano, 2003b), no siempre era suficiente y por ello se recurría a las demostraciones de júbilo que le dictara su patriotismo a la gente para la realización y el lucimiento de la conmemoración.

11 Hacen falta más estudios sobre las festividades desde el punto de vista de la historia económica. Simplemente tomando los donativos se podría analizar directamente quiénes dan dinero y cuánto aportan. Con esos datos se tendría que inferir por qué dona, qué obtienen de esas aportaciones, qué implican estas contribuciones en términos de prestigio, si son espontáneas, voluntarias, constantes o esporádicas, si son entregadas en especie, trabajo o numerario. Estos y otros aspectos merecen un estudio minucioso que rebasa las intenciones de este artículo pero que, sin duda, permitirá conocer más sobre las conmemoraciones.
La Junta Patriótica era, en principio, una organización plural, apolítica, voluntaria, democrática, pero en la realidad, en ciertos momentos, era un foro para el enfrentamiento de los grupos. Su composición, en términos numéricos, podía ser asombrosa. Además de una comisión permanente de nueve integrantes, había multitud de comisiones encargadas del trato con las autoridades y de las actividades preparatorias, centrales y complementarias. A eso se sumaban las llamadas comisiones recaudadoras que recorrían desde las altas esferas del gobierno hasta las pulquerías.

Los que habían contribuido a la realización de la festividad no sólo colaboraban con la patria, sino lo hacían en función de sus propios intereses. Las actas de las sesiones se publicaban en la prensa, con lo que atraían la confianza de la población por la transparencia de sus acciones. Como las listas de contribuyentes también se daban a conocer en la prensa, adquirían notoriedad que les podría redituar en un posicionamiento político o un beneficio económico. $Y$ a nosotros nos permiten conocer que en 1843 se lograron reunir cerca de tres mil pesos por concepto de donativos patrióticos (El Siglo Diez y Nueve, 7 de agosto de 1843). En cambio, en 1848 la Junta Patriótica hizo un verdadero esfuerzo para que la población, mermada por la reciente guerra contra Estados Unidos, contribuyera para la festividad. El resultado de la colecta se hizo público en la prensa (El Siglo Diez y Nueve, 9 de septiembre de 1848: 3). Con todo, peso a peso, únicamente se reunieron alrededor de 250.

Los donativos no sólo servían para costear las festividades sino para socorrer "a los inutilizados, viudas y huérfanos de los que murieron en defensa de la nación". Por ello, la Junta, considerando la escasez de fondos y lo corto de los donativos, acordó acercarse "a los empresarios del teatro, pidiendo se ceda el producto de una función de día de correo a beneficio de esta junta" para poderles entregar alguna gratificación. Tanto la empresa como los actores y músicos se prestaron gustosamente y la función se llevó a cabo el 20 de septiembre, en pre- 
sencia del presidente. Se juntaron 500 pesos que se repartirían el 26 por la tarde en la Universidad (El Siglo Diez y Nueve, 20 de septiembre de 1848: 4 y El Siglo Diez y Nueve, 25 de septiembre de 1848: 4).

La primera conmemoración de la Consumación de Independencia, a 16 años de distancia de la entrada del Trigarante, fue el 27 de septiembre de 1837. En ella se incluyeron varios actos centrales que se repetirían año con año. Por lo general, estas conmemoraciones seguían el esquema de las festividades del 16 de septiembre, inicio de la independencia, pero se introdujeron algunas variantes que le dieron especificidad a las fiestas.

Al rayar el alba, se harían descargas de artillería y repique de campanas para anunciar la aurora del fastuoso día. Algunos años a las nueve, otros a las diez de la mañana, la comitiva, que incluía a las autoridades de la ciudad y del país, así como a los integrantes de la Junta Patriótica y algunos destacados invitados, se dirigía desde las casas consistoriales hacia la catedral donde se cantaría "a toda orquesta, un solemne Te Deum" y se celebraría una misa de acción de gracias. El ritual religioso fue una constante que perduró mucho tiempo.

A continuación, la comitiva debería dirigirse "bajo de mazas" hacia el lugar donde se pronunciaría el discurso alusivo a la festividad. En 1837, la ceremonia se hizo en "el general de la nacional y pontificia Universidad". El orador Aguilar y Bustamante consideraba que, para terminar la guerra, se había presentado un amigo del pueblo “¿Quién? El libertador del nuevo mundo, el padre de la patria, el ídolo de los mexicanos, el ilustre Iturbide" (Aguilar de Bustamante, 1837: 114). Sí, Aguilar otorgaba a Iturbide el título de "padre de la patria" en 1837, honor que el Soberano Congreso Mexicano le había concedido a Hidalgo el 19 de abril de 1823 (Castillo Ledón, 2019).

En otros años se decidió que el discurso fuera al aire libre para permitir una mayor asistencia, por lo que la comitiva se dirigiría a la glorieta principal de la Alameda. "Al Ilegar la concurrencia a aquel sitio y cuando el orador haya concluido, habrá salvas de arti- llería” (El Siglo Diez y Nueve, 29 de septiembre de 1843: 1).

La nota periodística destacó que el recinto de la Universidad estaba "ricamente adornado, puesto a la cabeza el retrato del inmortal Hidalgo, a la derecha de la cátedra el del general libertador Iturbide y a la izquierda el del general presidente", Anastasio Bustamante (Diario del Gobierno de la República Mexicana, 28 de septiembre de 1837: 110-111). Los retratos suplían al gobernante en turno, cuando no era factible que estuviera presente en todos los lugares. Pero en el caso de las festividades, servían para recordar los rasgos de los héroes; su ausencia física se suplía con representaciones plásticas. Resultaría interesante analizar, en distintas etapas de la fiesta, quiénes eran los héroes seleccionados y cómo se les hermanaba con los personajes importantes del momento de la celebración.

Ese mismo año, en medio de las tropas ubicadas en la plaza, había una estatua de la Libertad "cuya base sostenía los retratos del primer jefe del ejército de las tres garantías, D. Agustín de Iturbide, del primer héroe militar de Dolores, D. Ignacio Allende y del benemérito general que arrancó las últimas banderas españolas de Ulúa, D. Miguel Barragán”. Notable es la ausencia, también en la iconografía, de Vicente Guerrero, militar insurgente y consumador de la independencia, aunque en 1855, su busto, como el de Iturbide, sería "llevado en triunfo al paseo" (La Verdad, 27 de septiembre de 1855: 1).

El elemento castrense fue central en los eventos conmemorativos del 27 de septiembre. Concluido el evento discursivo de 1837, al mediodía, las tropas de la guarnición formaron un cuadro en la plaza, y el presidente general les pasó revista. Aquellos que habían participado en la guerra formaron un cuadro al centro. El presidente los arengó, les repartió gratificaciones y posteriormente "desfilaron por el frente a Palacio todos los cuerpos de la guarnición".

Tres años después, tras escuchar el discurso en la Alameda, el presidente se dirigió al Ejido a pasar revista a las tropas que desde temprano habían estado ahí. Una vez que el 
presidente regresó a Palacio, las tropas marcharon a la plaza a recibir algunas remuneraciones y posteriormente desfilaron frente al balcón principal de palacio (Diario del Gobierno de la República Mexicana, 28 de septiembre de 1840).

En otros años, como 1858, la marcha de las tropas iniciaría desde la Calzada de la Piedad hasta la Acordada, ingresarían a la plaza desde la calle de Plateros y saldrían por la del Empedradillo, Santo Domingo, Cocheras y del Reloj (La Sociedad, 28 de septiembre de 1858). El desfile de tropas continuó en los siguientes años, pero adquirió un nuevo cariz en 1854, cuando se convirtió en un "simulacro de la entrada triunfal, que el libertador de México, el esclarecido patriota y caudillo de la Independencia, generalísimo don Agustín de Iturbide, hizo el día 27 de septiembre de 1821" (El Siglo Diez y Nueve, 10 de septiembre de 1854: 3). Repetirían el recorrido por las calles de San Francisco y Plateros, las cuales estarían extraordinariamente adornadas, para llegar a la plaza principal. Este acto, efectuado durante la presidencia de Santa Anna, se repitió en 1857 bajo la de Ignacio Comonfort, en el que él mismo participó "vestido de general de división", haciendo el recorrido desde Chapultepec para entrar triunfalmente al corazón de México (Malo, 1948: 497). Esta teatralización de los sucesos históricos se volvió una práctica repetida en ulteriores celebraciones de diversas fechas y son un poderoso método de insertar los elementos identitarios en el recuerdo de los que presencian tales actos.

Además de los rituales cívicos, las festividades incluían actos lúdicos que resultaran atractivos para la población que acudía a los festejos. Encontramos referencias a corridas de toros, juegos hidráulicos, equitación, bailes, acróbatas o simples paseos por la Alameda. $Y$ algo que fue muy llamativo fueron los globos aerostáticos, como el que se elevaría en 1844, con los "retratos de los héroes de la época" AHCDMX, 1844, Inv. 1067, Exp. 25). Los ciudadanos vieron volar por los aires a los héroes y llegar al mismísimo cielo.
Como parte de los actos complementarios de los rituales festivos podríamos considerar, por ejemplo, la inauguración de alguna obra pública, práctica que sería mucho más frecuente en la segunda mitad del siglo. En 1843 se colocó la primera piedra del Hospital Nacional de Inválidos, ubicado en la zona conocida como El Ejido (Diario del Gobierno de la República Mexicana, 27 de septiembre de 1843). En 1842, Antonio López de Santa Anna, a la sazón sentado en la silla presidencial durante el mes de septiembre, aprovechó la festividad para realizar un acto simbólico. Por la mañana del 27, después del discurso en la Alameda, se formó un paseo "hasta el Cementerio de Santa Paula, para conducir el pie que el General Santa Anna perdió en Veracruz, cuando la invasión francesa" (Malo, 1948: 214-215. Fowler, 2010: 294). Esa célebre ceremonia, más que un acto complementario, se volvió central arrebatando el protagonismo de Iturbide para centrarlo sobre el presidente (Zárate Toscano, 2003a).

Un luminoso componente de la festividad era la demostración de "los fuegos de artificio, en que, a más de cuatro árboles y otra multitud de juguetillos comunes, se figuró un castillo y cuatro fortines atacado por lanchas cañoneras, cuyo simulacro, llevado a la perfección, agradó demasiado" (Diario del Gobierno de la República Mexicana, 28 septiembre 1837: 110-111) El espectáculo luminoso solía empezar a las $8.30 \mathrm{y}$, una vez terminado, iniciaban las funciones de teatro, como sucedió en 1840.

Hubo años en que, además de la entrega de gratificaciones, desfiles y simulacros, se ofrecían banquetes a las tropas en la Calzada de la Piedad, a las que a veces asistía el presidente. También se organizaban comidas a los niños huérfanos a los que se les obsequiaban prendas de vestir (El Ómnibus, 16 de septiembre de 1856: 2).

En lo que respecta a la música festiva, parte fundamental en las festividades, tanto en sus rituales centrales como en los complementarios, se conoce una composición de José Antonio Gómez, titulada Pieza histórica sobre la Independencia de la 
nación mexicana (Gómez, 2015). ${ }^{12}$ Es una combinación de narración con música que va detallando los momentos anteriores a la Consumación y culmina con la entrada del Trigarante. Es prácticamente la única pieza musical conocida sobre el movimiento de Independencia y no hemos encontrado referencia de que se interpretara en alguna de las festividades. Lo que sí sabemos es que en 1831 se había presentado un himno con letra de Sierra Rosso y música de José Castel. No tenemos noticia de que se compusiera alguna otra pieza conmemorativa (Zárate Toscano, 2010). Pero sí sabemos, de acuerdo con el programa de 1848, que en el Teatro Nacional, el 27 de septiembre, para solemnizar la festividad del día, "se representará la Norma, ópera del maestro [Vincenzo] Bellini" (El Siglo Diez y Nueve, 25 de septiembre de 1848: 4). ${ }^{13}$

A estas funciones de ópera solían asistir el presidente, su gabinete, integrantes de lo más granado de la sociedad, pero también había secciones a precios más económicos a las que podían asistir personas con menores ingresos. Y no descartamos la posibilidad de que circularan algunas canciones populares alusivas a los sucesos, con tonos críticos e irónicos que, lamentablemente no se han conservado.

Además de esta música selecta, las crónicas con frecuencia mencionan la presencia de músicos instalados en las plazas ejecutando algunas piezas, acompañando a las autoridades a los espacios de festejo o simplemente recorriendo las calles, es decir, haciendo sonar las notas en espacios públicos y abiertos. En 1844 se especificó que, por la tarde, habría músicas militares en los paseos de la Independencia y en la Alameda y que en la noche se situarían en la plaza de la Constitución para dar serenata, mientras que seis años después se especificaba que serían los músicos de distintos batallones (AHCDMX, 1844, Inv. 1067, Exp. 25 y El Monitor Republi-

12 La edad de Gómez tal vez esté equivocada. La publicó por entregas Ignacio Cumplido entre 1843 y 1844 aunque en la Biblioteca del Palacio existe un ejemplar de la obra completa, pero sin fecha.

13 La Norma se estrenó en el Teatro "La Scala de Milán" el 26 de diciembre de 1831, y en México fue en el Teatro Principal en 1836 cano, 16 de septiembre de 1850, n. 1942). Estos actos eran los festejos en los que podría participar el pueblo sin tantas restricciones.

No podemos pasar por alto que la fiesta es de quien la organiza, de quien la paga y de eso depende su orientación y significado, factor que se une al momento coyuntural en que se conmemora. Pero además se ha hecho evidente que se requieren muchas voluntades para organizar y llevar a cabo una festividad.

\section{Conclusiones}

Aunque no se menciona en las festividades de los primeros años, para su entrada triunfal a la ciudad de México, Iturbide escogió exactamente el día que cumplió 38 años, fecha a la que le atribuyó un doble significado, como el día en que él había visto la luz y también el día que nacía el México independiente. Sin embargo, esta feliz coincidencia prácticamente no se destacó, sino hasta 1883 en la que se efectuaron los festejos del centenario de su nacimiento.

No es fácil identificar qué grupo está detrás de la exaltación de Iturbide ya que, contrario a lo que tradicionalmente se repetía, durante el siglo XIX los mexicanos no se dividieron simplemente en conservadores y liberales, sino que hubo diversas variantes, modalidades, tenues o marcadas diferencias entre los distintos grupos que luchaban por detentar el poder. ${ }^{14}$ Algunas acciones de Iturbide lo podían hacer apreciado por un sector de los políticos y odiado para otros. Pero también era factible que la división entre unos y otros fuera una tenue línea. Finalmente, la Consumación de Independencia representaba la reconciliación de bandos enfrentados, de rivales. Y tal vez al conmemorarla eso era lo que se busca, dejar atrás los enfrentamientos y unirse para lograr un bien común.

No podemos pasar por alto que una de las finalidades de las festividades era inculcar un sentimiento de pertenencia al recién na-

\footnotetext{
14 Este reduccionismo omite los matices y las variantes que impiden etiquetarlos de manera tan estricta y no permite visualizar que su manera de pensar y su actuar no era tan opuesto.
} 
cido país, y así contribuir a la conformación de la identidad nacional señalando algunos hitos fundacionales. De hecho, la selección del inicio de la guerra de Independencia o de su Consumación representa distintas posiciones políticas que se enfrentaron durante el siglo XIX. Encarnan la oposición entre recuerdo y olvido $\mathrm{y}$, mediante la selección de elementos que contribuyeran a la consecución de intereses políticos inmediatos. Sin embargo, en este caso particular, algunos regímenes buscaron asegurar un lugar en la historia para Agustín de Iturbide (Florescano, 1994). Podría decirse que los héroes se mueren varias veces, siendo la primera vez al momento de su desaparición física.

En este caso, el hecho de que hubiera sido fusilado, proporcionaba elementos a sus seguidores para resaltar que se había cometido un injusto asesinado, mientras que a sus enemigos les ayudaba a confirmar que había muerto por traicionar a la patria. Así que el héroe también podía morir cuando los regímenes contrarios a él lo sumían en el olvido o lo relegaban a un plano menor.

Dado que Iturbide era un militar de reconocida trayectoria, la festividad del 27 de septiembre adquirió relevancia para el elemento castrense que había participado en ambos bandos de la lucha. $Y$ en las festividades, llenaba las calles de marcialidad al reproducir desfiles, paradas, incluso simulacros. Finalmente, durante buena parte del siglo XIX, los militares eran quienes podrían garantizar o perturbar el orden.

En cierto sentido, podríamos considerar que las festividades buscaran ser un medio de cohesión social, que permitiera olvidar las diferencias para que todos los sectores pudieran celebrar. Pero en términos políticos, las diferencias entre los grupos o nacientes partidos los enfrentaban, también, en los momentos que deseaban celebrar y que les proporcionaban sustento ideológico para su existencia. No es gratuito que fueran periódicos de tendencia conservadora y católica quienes más recordaran a Iturbide, incluso cuando la festividad se hubiera suprimido oficialmente en 1864. Las rememoraciones de la Consumación de la Inde- pendencia y de su héroe se limitarían a la celebración de misas en memoria de Iturbide. Esta costumbre había iniciado en 1845 $y$, durante la segunda mitad del XIX, fue prácticamente el único acto conmemorativo efectuado el 27 de septiembre, pero no en espacios abiertos, civiles, oficiales, sino al interior de las iglesias, ya fuera en catedral, donde reposaban los restos del consumador, o en la profesa (Malo, 1948: 285).

La espectacularidad de la festividad y los recursos invertidos en su realización serían factores que buscarían la permanencia de determinadas fechas en la memoria. Las variaciones vendrían en la manera en la que los detentadores del poder deseaban que quedara en el recuerdo. En cierto sentido, las conmemoraciones fueron los mecanismos de campaña de los diferentes grupos políticos que se disputaron el poder en el siglo XIX y por lo tanto tenían que ser organizadas de manera escrupulosa y vistosa.

La festividad cívica era el momento idóneo para, a través de un discurso, refrescar la historia en la mente de los escuchas. Y de esta forma, las festividades se han convertido en un lugar de memoria, que busca fijar en el recuerdo los elementos identitarios del país en sus distintas épocas históricas, aquellos que buscan exaltar el nacionalismo entre la población. Al estudiar el panteón de héroes de cada época, tenemos elementos para comprender las intenciones de cada régimen político que destaca a algunos y relega a otros, algo que no ha dejado de suceder.

\section{Fuentes consultadas}

Aguila Mejicana (1827), "Mejico 27 de setiembre”, 27 de septiembre, México, año V, n. 270, p. 4.

Aguila Mejicana (1825), "Méjico 27 de agosto. Solemnidad nacional", 28 de agosto, México, año III, n. 135, p. 1.

Aguilar de Bustamante, José María (1837), "Discurso pronunciado por el ciudadano lic. José María Aguilar de Busta- 
mante el 27 de setiembre de 1837 en el general de la Nacional y Pontificia Universidad, en fausto recuerdo de la entrada a esta capital del ejercito Trigarante con su primer jefe en solemne aniversario de la Consumación de la Independencia", Diario del Gobierno de la República, 29 de septiembre, México, t. IX, núm. 883, p. 1.

América Poética (1846), Colección escogida de composiciones en verso, escritas por americanos en el presente siglo, Valparaíso, Imprenta del Mercurio.

AHCDMX (Archivo Histórico de la Ciudad de México) (1864), Fondos Municipales, Guadalupe Hidalgo, Festividades, inv. 93, exp. 34.

AHCDMX (Archivo Histórico de la Ciudad de México) (1844), Fondos Municipales, Festividades 15 y 16 de septiembre, inv. 1067, exp. 25.

Blanco, Santiago (1849), Discurso pronunciado en la alameda de esta capital el 27 de septiembre de 1849, por el general D. Santiago Blanco, en el aniversario de la Consumación de la Independencia nacional, México, Imprenta de Ignacio Cumplido.

Cañedo Gamboa, Sergio y Salazar Mendoza, Flor de María (2010), Discursos patrióticos de la independencia en San Luis Potosí, de la primera república federal a la república restaurada, 1827-1872, San Luis Potosí, El Colegio de San Luis-LIX Legislatura del H. Congreso del Estado de San Luis Potosí-Secretaría de Cultura del Gobierno del Estado de San Luis Potosí.

Carbajal López, David (2017), "De la Catedral al cementerio y de la procesión al desfile: festejos nacionales cívico-religiosos en México, 1826-1842", en Dalila Chine-Lehmann y Natalia Molinaro (coords.), Amérique Latine Histoire et Mémoire. Les Cahiers ALHIM, núm. 33, doi: https://doi.org/10.4000/alhim. 5650
Castillo Ledón, Luis (2019), Hidalgo. La vida del héroe, México, Fondo de Cultura Económica-Cámara de Diputados, Colección Historia.

Connaughton, Brian (2005), "Entre la palabra hablada y la palabra escrita: La cultura política nacional en el foro de la Alameda, 1827-1854", Estudios del Hombre, núm. 20, Guadalajara, Universidad de Guadalajara/Departamento de Estudios Mesoamericanos y Mexicanos del Centro Universitario de Ciencias Sociales y Humanidades, pp. 117-152.

Connaughton, Brian (1995), "Ágape en disputa: fiesta cívica, cultura política regional y la frágil urdimbre nacional antes del Plan de Ayutla", Historia Mexicana, 45 (2), México, El Colegio de México, pp. 281-316.

Costeloe, Michael (1997), "La Junta Patriótica y la celebración de la Independencia en la ciudad de México, (1825-1855)", Memorias de la Academia Mexicana de la Historia, correspondiente de la Real de Madrid, tomo XL, México, Academia Mexicana de la Historia, pp. 125-152.

Del Castillo Velasco, José María (1855), "Oración cívica, pronunciada en la Alameda de México por el C. Lic. José María del Castillo Velasco, el 27 de setiembre de 1855, aniversario de la entrada triunfal del Ejército Trigarante", El Monitor Republicano, 27 de septiembre, México, Año X, n. 2943, p. 1.

De la Torre Villar, Ernesto (comp.) (1988), La conciencia nacional y su formación: discursos cívicos septembrinos, 1825-1871, México, Universidad Nacional Autónoma de México/Coordinación de Humanidades.

Denegre Vaught Alcocer, Jorge Ramiro (compilador y comentarista) (2011), Dos siglos de discursos patrióticos, México, Universidad Nacional Autónoma de México/Instituto de Investigaciones Jurídicas, Colección Denegre Vaught Peña. 
Diario del Gobierno de la República Mexicana (1843),"México, septiembre 28 de 1843", 28 de septiembre, México, t. XXVII, n. 3019, p. 111.

Diario del Gobierno de la República Mexicana (1843), "México, septiembre 27 de 1843", 27 de septiembre, México, t. XXVII, n. 3018, p. 88.

Diario del Gobierno de la República Mexicana (1840), "México, septiembre 28 de 1840", 28 de septiembre, México, t. XII, n. 1247, p. 88.

Diario del Gobierno de la República Mexicana (1838), "se ha celebrado...", 28 de septiembre, México, t. XII, n. 1247, p. 112.

Diario del Gobierno de la República Mexicana (1837), "Comisión permanente de la Junta Patriótica", 27 de septiembre, México, t. IX n. 881, p. 108.

Diario del Gobierno de la República Mexicana (1837), "Comisión permanente de la Junta Patriótica", 28 de septiembre, México, t. IX, n. 882, pp. 110-111.

Dublán, Manuel y Lozano, José María (1880), Legislación Mexicana, [decreto 6 de septiembre de 1843], México, Imprenta del Comercio, t. IV, n. 2657.

Dublán, Manuel y Lozano, José María (1876a), Legislación Mexicana, [decreto 16 de agosto de 1822], México, Imprenta del Comercio, t. I, n. 311.

Dublán, Manuel y Lozano, José María (1876b), Legislación Mexicana, [decreto 27 de noviembre 1824], México, Imprenta del Comercio, t. I, n. 442.

Departamento del Distrito Federal-Dirección General de Acción Social (1955), El Evangelio de la Patria, México, 10 tomos.

El Monitor Republicano (1850), "El Monitor", 16 de septiembre, México, año VI, n. 1942, pp. 3-4.

El Siglo Diez y Nueve (1861), "Diversiones públicas", 27 de septiembre, México, año XXI, 6a época, t. II, n. 256, p. 4.
El Siglo Diez y Nueve (1861), "Diversiones públicas", 16 de septiembre, México, año XXI, 6a época, t. II, n. 245, p. 4.

El Siglo Diez y Nueve (1854), "Festividades Nacionales", 10 de septiembre, México, año XIV, 4a época, t. VIII, n. 2085, p. 3.

El Siglo Diez y Nueve (1848), "Junta patriótica”, 25 de septiembre, México, año VII, trim. II, 4a época, n. 117, p. 4.

El Siglo Diez y Nueve (1848), "Función de teatro a beneficio de las viudas y huérfanos de los que murieron por la patria", 20 de septiembre, México, año VII, trim. II, 4a época, n. 112, p. 4.

El Siglo Diez y Nueve (1848), "Junta Patriótica de México", 9 de septiembre, México, año VII, trim. II, 4⿳a época, n. 101, p. 2.

El Siglo Diez y Nuev (1844), "27 de septiembre", 27 de septiembre, México, año III, trim. III, 2a época, n. 1027, p. 2.

El Siglo Diez y Nueve (1843), "Interior", 30 de septiembre, México, año II, trim. II, 2a época, n. 674, p. 2.

El Siglo Diez y Nueve (1843), "México, septiembre 29 de 1843", 29 de septiembre, México, año II, trim. II, 2a época, n. 673, p. 1.

El Siglo Diez y Nueve (1843), "Junta patriótica para celebrar el Aniversario de la Independencia", 7 de agosto, México, año II, trim. II, 2a época, n. 621, p. 2.

El Ómnibus (1856), "Crónica”, 16 de septiembre, México, año VI, t. VI, n. 213, p. 2.

Fernández de Jáuregui, Juan Manuel (1860), "Discurso pronunciado en la Alameda de México el día 27 de setiembre de 1860, por el Sr. Lic. D. Juan Manuel Fernández de Jáuregui", La sociedad, periódico político y literario, 28 de septiembre, México, t. VI, n. 1000, p. 1.

Florescano, Enrique (1994), "Les origines de la mémoire nationale. La célebration du triomphe de l'independance de 1821", en François Xavier Guerra, (ed.), Mémoires en devenir. Amérique latine 
XVle-XX siécle, Bordeaux, Maison des Pays Iberiques, pp. 157-176.

Fowler, Will (2010), Santa Anna, Xalapa, Universidad Veracruzana.

Fowler, Will (1998), México in the Age of Proposals, 1821-1863, Westport and London, Greenwood Press.

Garrido Aspero, María José (2001), "Cada quien sus héroes", Estudios de Historia Moderna y Contemporánea de México, 22 (22), México, Universidad Nacional Autónoma de México/Instituto de Investigaciones Históricas, pp. 5-22.

Godoy, José María (1846), "Discurso pronunciado el día 27 de septiembre de 1846, en la Alameda de México, por el ciudadano Lic. José María Godoy, en el aniversario solemne de la Consumación de la Independencia nacional, verificada el 27 de septiembre de 1821", El Monitor Republicano, 30 de septiembre, 1 y 2 de octubre, México, núms. 587, 588 y 589, p. 3.

Gómez, José Antonio (2015), Pieza histórica sobre la independencia de la nación mexicana, puesta en música para el pianoforte con acompañamiento de violín, a flauta y violoncelo, por el joven americano profesor de música, J. Ant. Gómez y Olguin de edad de 13 años, quien la dedica a todos los habitantes de su amada patria, revisión y edición Lidia Guerberof Hahn, México, Conaculta-Centro Nacional de Investigación, Documentación e Información Musical.

González Mendoza, José (1848), "Discurso pronunciado el 27 de septiembre de 1848, por el ciudadano J, M. González Mendoza, en el aniversario de la Consumación de la Independencia nacional", El Siglo XIX, 27 de septiembre, México, año VII, trim. 2, 4a época, pp. 1-2.

González Pérez, Marcos (1995), Bajo el palio y el laurel. Bogotá a través de las manifestaciones festivas decimonónicas, Bogotá, Fondo Editorial Universidad Distrital Francisco José de Caldas.
Guedea, Virginia (coord.) (2009), Asedios a los centenarios (1910-1921), México, Fondo de Cultura Económica-Universidad Nacional Autónoma México.

Herrejón Peredo, Carlos (2003), Del sermón al discurso cívico: México, 1760-1834, Zamora, El Colegio de Michoacán-El Colegio de México.

La Sociedad (1858), "La festividad de ayer", 28 de septiembre, México, t. II, n. 271, 2 ${ }^{\text {a }}$ época, p. 3.

La Verdad (1855), "Solemnidades cívicas", 27 de septiembre, México, n. 30, p. 1.

Lafragua, José María (2014), Miscelánea de Política (selección), México, Cámara de Diputados LXII Legislatura, Pámpano Servicios Editoriales, (Biblioteca del Pensamiento Legislativo y Político Mexicano).

Lafragua, José María (1843), Arenga cívica pronunciada el día 27 de septiembre de 1843 en la Alameda de México por el ciudadano Licenciado D. José María Lafragua en memoria de la gloriosa Consumación de la Independencia, México, Imprenta de Vicente García Torres.

Malo, José Ramón (1948), Diario de sucesos notables (1832-1853), arreglados y anotados por el P. Mariano Cuevas, S. J., México, Editorial Patria.

Monterde, José Mariano (1852), Oración cívica pronunciada en la Alameda de México el 27 de septiembre de 1852, por el sr. General D. José Mariano Monterde, director del Colegio Militar, México, Imprenta de Ignacio Cumplido.

Moreno Juárez, Sergio (2012), "La infancia mexicana en los dos centenarios de la Independencia Nacional (Ciudad de México, 1910 y 1921)", Historia Mexicana, LXII (1), México, El Colegio de México, pp. 305-365.

Navarro e Ibarra, Joaquín (1845), "Discurso pronunciado en la Alameda de esta capital por el ciudadano Joaquín Navarro e Ibarra, del 27 de septiembre de 1845. 
Solemne aniversario de la entrada del ejercito Trigarante en México, el año de 1821", El Siglo Diez y Nueve, 27 de septiembre, México, año VI, trim. II, n. 1399, 3época, pp. 1-2.

Nora, Pierre (1984-1992), Les lieux de mémoire, vol. 1: la Republique, Paris, Gallimard.

Plasencia de la Parra, Enrique (1991), Independencia y nacionalismo a la luz del discurso conmemorativo 1825-1867, México, Consejo Nacional para la Cultura y las Artes, Serie Regiones.

Priego, Arturo y Hernández, Begoña (1985), Celebración del grito de independencia: recopilación hemerográfica 1810-1985, México, Instituto Nacional de Estudios Históricos de las Revoluciones de México.

Prieto, Guillermo (1844), "Discurso que en la solemnidad del 27 de septiembre de 1844, pronunció en la Alameda de México el ciudadano Guillermo Prieto, empleado en la renta del tabaco", El Siglo Diez y Nueve, 27 de septiembre, México, Año 3, n. 1037, p. 3.

Ramírez, Ignacio (1861), "Discurso cívico pronunciado por el C. Lic. Ignacio Ramírez el 16 de setiembre de 1861 en la Alameda de México en memoria de la proclamación de la independencia", El Siglo Diez y Nueve, 18 de septiembre, México, Año XXI, t. 2, n. 247, p. 1.

Rangel, Joaquín (1851), Oración cívica pronunciada el 27 de setiembre de 1851, por el C. general Joaquín Rangel, en conmemoración de la Independencia de México, México, Imprenta de Ignacio David, dirigida por A. Contreras.

Sánchez de Tagle, Agustín (1854), "Oración cívica pronunciada en la Alameda de México el día 27 de septiembre de 1854, por D. Agustín Sánchez de Tagle, caballero de la nacional y distinguida Orden de Guadalupe", El Siglo Diez y Nueve, 27 de septiembre, México, Año 14, t. 8. n. 2102, p. 2.
Sierra y Rosso, Ignacio (1831), "Himno Cívico, que a la celebridad de la gloriosa entrada del ejército trigarante en la ciudad de México, el día 27 de septiembre de 1821, dedico el ciudadano Ignacio Sierra y Rosso y puso en música a grande orquesta el profesor ciudadano José Castel, individuo de la de este teatro donde se cantó la noche de ayer", El Sol, 28 de septiembre, México, año 3, n. 820, pp. 3279-3280.

Tapia R-Esparza, Francisco Javier (2010), "Los festejos del primer centenario de la Consumación de la Independencia, nuevo impulso para el Catolicismo Social", Tzintzun, núm. 52, Morelia, Universidad Michoacana de San Nicolás de Hidalgo, pp. 11-45.

Tornel y Mendívil, José María (1850), "Discurso pronunciado en la alameda de la ciudad de México en el día 27 de Setiembre de 1850, por el ciudadano, senador, general de división José María Tornel y Mendivil", El Monitor Republicano, 29 de septiembre, México, año VI, n. 1955, pp. 2-3.

Vázquez Mantecón, María del Carmen (2008), "Las fiestas para el libertador y monarca de México Agustín de Iturbide, 1821-1823", Estudios de Historia Moderna y Contemporánea de México, núm. 36, México, Universidad Nacional Autónoma de México/Instituto de Investigaciones Históricas, pp. 45-83.

Vásquez Meléndez, Miguel Ángel (2012), México personificado: un asomo al teatro del siglo XIX, México, Instituto Nacional de Bellas Artes-Centro Nacional de Investigación, Documentación e Información Teatral "Rodolfo Usigli".

Zárate Toscano, Verónica (2013), "El amor a la patria en la ciudad de México decimonónica (1825-1850)", en Pilar Gonzalbo (coord.), Amor e historia. La expresión de los afectos en el mundo de ayer, México, El Colegio de México-Centro de Estudios Históricos, pp. 381-408.

Zárate Toscano, Verónica (2010), "La música conmemorativa en el México decimonónico", núm. 97, México, Artes de 
México. Música de la Independencia a la Revolución, pp. 34-43.

Zárate Toscano, Verónica (2007), "Las pervivencias de Iturbide en el México de hoy", Millars, Espai i Història, 11 (30), Dossier "La independencia y el desarrollo del Estado mexicano: política, cultura y sociedad", Castellón, Universitat Jaume I, pp. 105-122.

Zárate Toscano, Verónica (2004), "La conformación de un calendario festivo en México en el siglo XIX", en Erika Pani y Alicia Salmerón (coords.), Conceptuar lo que se ve. Francois-Xavier Guerra, historiador. Homenaje, México, Instituto Mora, pp. 182-214.

Zárate Toscano, Verónica (2003a), "Héroes y fiestas en la ciudad de México en el siglo XIX: la insistencia de Santa Anna", en Manuel Chust, Víctor Minguez (eds.), La construcción del héroe en España y México. 1789-1847, Valencia, Publicacions de la Universitat de Valencia-Universidad Autónoma de México-Iztapalapa-Universidad Veracruzana-El Colegio de Michoacán, pp. 133-153.

Zárate Toscano, Verónica (2003b), "Las conmemoraciones septembrinas en la ciudad de México y su entorno en el siglo XIX", en Verónica Zárate Toscano (coord.), Política, casas y fiestas en el entorno urbano del Distrito Federal, siglos XVIII-XIX, México, Instituto Mora, pp. 129-196.

Zárate Toscano, Verónica (1994) “Agustín de Iturbide: entre la memoria y el olvido", Secuencia, núm. 28, México, Instituto Mora, pp. 5-27.

Recibido: 21 de junio de 2021. Reenviado: 15 de julio de 2021. Aceptado: 3 de agosto de 2021.

\section{Verónica Zárate Toscano}

Es doctora en Historia por El Colegio de México. Actualmente es profesora-investigadora en el Instituto Mora. Es miembro del Sistema Nacional de Investigadores, nivel II. Desde sus primeras investigaciones ha abordado el estudio de la prensa en el periodo de la Independencia, tanto en México como en España. De igual manera se ha interesado por la historia de las mentalidades y de la vida cotidiana. Sus líneas de investigación se enfocan en temas relacionados con la materialización de la memoria histórica a través del estudio de monumentos, nomenclatura, festividades, música, etcétera. Entre sus más recientes publicaciones destacan, como autora: "La historia intelectual en México y sus conexiones", Varia Historia, 31 (56), Minas Gerais, Universidad Federal de Minas Gerais, pp. 401-422 (2015); Diálogo con historiadores. Reflexiones en torno al tiempo, el espacio y la memoria, Gozos y sufrimientos en la historia de México, México, Instituto Mora (2014); y como co-coordinadora: Política, casas y fiestas en el entorno urbano del Distrito Federal, siglos XVIII-XIX y una docena de visiones de la historia. Entrevistas con historiadores americanistas, México, El Colegio de México-Instituto de Investigaciones Dr. José María Luis Mora (2007). 